\title{
AN EPIDEMIOLOGICAL STUDY OF TOBACCO USE AMONG MALES ABOVE 15 YEARS OF AGE IN AN URBAN AREA OF MEERUT DISTRICT
}

\author{
Arun Kumar Pandey1, Mohammad Intekhab Alam Chand ${ }^{2}$
}

${ }^{1}$ Assistant Professor, Department of Community Medicine, Katihar Medical College, Katihar, Bihar. ${ }^{2}$ Assistant Professor, Department of Community Medicine, Katihar Medical College, Katihar, Bihar.

\begin{abstract}
\section{BACKGROUND}

In India, approximately 5500 children and adolescents start using tobacco products daily, some as young as 10 years old. The majority of users have first use tobacco prior to the age of 18 years. Uttar Pradesh shows a high tobacco use, smoking being more popular than chewing.
\end{abstract}

\section{OBJECTIVES}

1. To find out the prevalence of tobacco use among males above 15 years of age.

2. To assess the sociodemographic and other correlates on tobacco use.

\section{MATERIALS AND METHODS}

Out of 10,000 population residing in urban field practice area, number of males above 15 years of age was 3800 . A sampling of eligible subjects was done by systematic random sampling technique, including every $4^{\text {th }}$ male in study.

\section{RESULTS}

The prevalence of tobacco use is $54.68 \%$, among which $28.12 \%$ are smoking and $26.56 \%$ are using smokeless form of tobacco. The prevalence is more in upper socioeconomic status (38.70\%) than lower socioeconomic status (25\%), more in nuclear families as comparison to joint family and in non-vegetarian as comparison to vegetarians. There is also an association between literacy and tobacco use; more in illiterate persons as comparison to those who are educated for more than high school.

\section{CONCLUSIONS}

This study shows that the prevalence of tobacco use is high among nuclear families, high socioeconomic status, unmarried people, non-vegetarians and illiterate persons.

\section{KEYWORDS}

Smoking/Smokeless Tobacco/Socioeconomic Status.

HOW TO CITE THIS ARTICLE: Pandey AK, Chand MIA. An epidemiological study of tobacco use among males above 15 years of age in an urban area of Meerut district. J. Evolution Med. Dent. Sci. 2016;5(79):5911-5914, DOI: 10.14260/jemds/2016/1334

\section{BACKGROUND}

Tobacco use kills nearly six million people worldwide each year. According to the World Health Organization (WHO) estimates, globally, there were 100 million premature deaths due to tobacco in the $20^{\text {th }}$ century, and if the current trends of tobacco use continue, this number is expected to rise to 1 billion in the $21^{\text {st }}$ century ${ }^{1}$. Tobacco smoking is among the largest preventable causes of premature deaths globally. ${ }^{1}$ In 2010, an estimated 120 million Indian adults smoked, making India second only to China in number of smokers. ${ }^{2}$ The consumption pattern of tobacco has likely changed over the last decade in response to substantially higher income in India paired with population growth and perhaps in response to modest tobacco control efforts. ${ }^{3}$ According to the National Family Health Survey (NFHS)-3 survey, conducted in

Financial or Other, Competing Interest: None.

Submission 25-08-2016, Peer Review 18-09-2016,

Acceptance 24-09-2016, Published 03-10-2016.

Corresponding Author:

Dr. Arun Kumar Pandey,

Assistant Professor,

Department of Community Medicine,

Katihar Medical College,

Katihar, Bihar.

E-mail: drarunpandey80@gmail.com

DOI: $10.14260 /$ jemds $/ 2016 / 1334$

\section{(c) (i) $\odot$}

2005-06, tobacco use is more prevalent among men, rural population, illiterates, poor and vulnerable section of the society. 4 The estimates of the Global Adult Tobacco Survey (GATS) conducted among persons 15 years of age or older during $2009-10$ indicate that $34.6 \%$ of the adults $(47.9 \%$ males and $20.3 \%$ females) are current tobacco users. Fourteen percent of the adults smoke $(24.3 \%$ males and $2.9 \%$ females) and $25.9 \%$ use smokeless tobacco (32.9\% males and $18.4 \%$ females). ${ }^{2}$

Tobacco is deadly in any form or disguise. Scientific evidence has unequivocally established that exposure to tobacco smoke causes death, disease and disability. ${ }^{5}$ Forty percent of the tuberculosis burden in India may be attributed to smoking.

Significant association is seen between passive or active exposure to tobacco smoke and tuberculosis infection, disease and tuberculosis mortality. ${ }^{6}$ Pednekar et al in their Mumbai cohort found that the incidence of oral cancers was $42 \%$ higher among bidi smokers as compared with cigarette smokers. ${ }^{7}$ Smokeless tobacco use was associated with cancers of the lip, oral cavity, pharynx, digestive, respiratory and intrathoracic organs. ${ }^{8}$ There is need to improve knowledge and awareness about bad effects of tobacco use in Rural as well as Urban areas through various IEC activities. The objectives of the present study were: (1) To find out the prevalence of tobacco use among males above 15 years of 
age. (2) To assess the sociodemographic and other correlates on tobacco use.

\section{METHODOLOGY}

The present study was conducted at the Urban Health Training Centre, Surajkund, Meerut, which is the Urban Health Training Centre of the Department of Community Medicine, LLRM Medical College, Meerut.

The Urban Health Training Center, Surajkund caters a total population of 9971 residing in approximately 1781 families.

Appropriate simple random sample of size (n) within 95\% confidence limit may be obtained by using the following formula:

$$
\mathrm{n}=\frac{\mathrm{Z}^{2} \times \mathrm{P} \times \mathrm{Q} \times \mathrm{DEFF}}{\mathrm{d}^{2}}
$$

Where $\mathrm{Z}=($ Value of $\mathrm{Z}$ at $95 \%=1.96)$

$\mathrm{P}=$ Prevalence.

$\mathrm{q}=(100-\mathrm{P})$.

$\mathrm{d}=$ Probable error (absolute or relative precision).

$\mathrm{DEFF}=$ Design Effect (1 for SRS).

By using 30\% anticipated prevalence use among males of 15 years and above with $10 \%$ relative precision, following sample size was obtained for the study:

$$
\begin{gathered}
\mathrm{n}=\frac{(1.96)^{2} \times 30 \times(100-30)}{10 \% \text { of } 30 \times 10 \% \text { of } 30} \\
=\frac{3.84 \times 30 \times 70}{3 \times 3}
\end{gathered}
$$

Out of 10,000 population residing in urban field practice area, number of males above 15 years of age was 3800 . Since population is large, scattered and complete list of population was available, a sampling of eligible subjects was done by systematic random sampling technique including every $4^{\text {th }}$ male in study. If sampled individual was not available for study due to any reason, e.g. absent, not willing to participate, etc., then the next individual was included for study.

The desired information viz. tobacco use, disability due to tobacco use, other factors pertaining to tobacco use was collected on a predesigned interview schedules. Voluntary, written consent was obtained from all subjects.

The desired information viz. tobacco use, disability due to tobacco use, other factors pertaining to tobacco use was collected on a predesigned interview schedules. Data was analysed using statistical package for the social sciences (SPSS) software 22.0.0 (License Code9DNCAF203QVDV7FBI0696006GWLNXZPPRYTPWF2PPX7C 8T6Y24LMVV2ET7DOLX5CXAL5YDLL79UPGEFCPDXP5Q805 E). As this study did not involve any patients or patient's records, the institutional ethical committee intimated that ethical clearance was not required.

\section{OBSERVATION AND RESULTS}

In the present study, the total sample size was 896 and out of

\begin{tabular}{|c|c|c|}
\hline Form of Tobacco Use & No. & Percentage (\%) \\
\hline Tobacco Smoking & 252 & 28.12 \\
\hline Smokeless tobacco & 238 & 26.56 \\
\hline Total & 896 & 54.68 \\
\hline
\end{tabular}
these 490 persons $(54.68 \%)$ are found to be using one or more form of tobacco.

\begin{tabular}{|c|c|c|c|c|c|c|}
\hline \multirow{2}{*}{ Sl. No. } & \multirow{2}{*}{ Age } & \multirow{2}{*}{ No. } & \multicolumn{2}{|c|}{ Smoking } & \multicolumn{2}{|c|}{ Smokeless } \\
\hline & & & No. & $\%$ & No. & $\%$ \\
\hline 1. & $15-19$ & 180 & 22 & 12.15 & 18 & 9.94 \\
\hline 2. & $20-24$ & 176 & 27 & 15.34 & 39 & 22.15 \\
\hline 3. & $25-29$ & 141 & 39 & 27.65 & 42 & 29.78 \\
\hline 4. & $30-39$ & 125 & 46 & 36.8 & 42 & 33.6 \\
\hline 5. & $40-49$ & 113 & 50 & 44.24 & 40 & 35.39 \\
\hline 6. & $50-59$ & 94 & 43 & 45.74 & 33 & 35.1 \\
\hline 7. & $60+$ & 66 & 25 & 37.87 & 24 & 36.36 \\
\hline 8. & Total & 896 & 252 & 28.12 & 238 & 26.56 \\
\hline \multirow{3}{*}{\multicolumn{3}{|c|}{$\chi^{2}$}} & \multicolumn{2}{|c|}{$\chi^{2}=73.81$} & \multicolumn{2}{|c|}{$\chi^{2}=42.59$} \\
\hline & & & \multicolumn{2}{|c|}{$\mathrm{df}=6$} & \multicolumn{2}{|c|}{$\mathrm{df}=6$} \\
\hline & & & \multicolumn{2}{|c|}{$\mathrm{p}<.001$} & \multicolumn{2}{|c|}{$\mathrm{p}<.001$} \\
\hline
\end{tabular}

Out of 490 subjects, 252 (28.12\%) were smoking tobacco while (238) $26.56 \%$ are using smokeless form of tobacco.

The prevalence of tobacco use was minimum in age group of 15-19 years with the prevalence of smoking and smokeless tobacco use of $12.15 \%$ and $9.94 \%$ respectively and the prevalence of tobacco use gradually increases with increasing age with minor variations being maximum in age group of 5059 years with the prevalence of smoking and smokeless tobacco use of $45.74 \%$ and $35.10 \%$ respectively and significant fall in overall prevalence of tobacco use after attaining the age of 60 years. The prevalence of tobacco use in

\begin{tabular}{|c|c|c|c|c|c|c|}
\hline \multirow{2}{*}{$\begin{array}{l}\text { Sl. } \\
\text { No. }\end{array}$} & \multirow{2}{*}{$\begin{array}{l}\text { Socio- } \\
\text { Economic } \\
\text { Status }\end{array}$} & \multirow{2}{*}{ No. } & \multicolumn{2}{|c|}{ Smoking } & \multicolumn{2}{|c|}{ Smokeless } \\
\hline & & & No. & $\%$ & No. & $\%$ \\
\hline 1 & Upper & 31 & 12 & 38.7 & 11 & 35.48 \\
\hline 2 & Upper Middle & 503 & 147 & 29.22 & 138 & 27.43 \\
\hline 3 & Lower Middle & 179 & 51 & 28.49 & 52 & 29.05 \\
\hline 4 & Upper Lower & 163 & 37 & 22.69 & 34 & 20.85 \\
\hline \multirow[t]{2}{*}{5} & Lower & 20 & 5 & 25 & 3 & 15 \\
\hline & & 896 & 252 & 28.12 & 238 & 26.56 \\
\hline \multirow{3}{*}{\multicolumn{3}{|c|}{$\chi^{2}$}} & \multicolumn{2}{|c|}{$\chi^{2}=75.53$} & \multicolumn{2}{|c|}{$\chi^{2}=6.12$} \\
\hline & & & \multicolumn{2}{|c|}{$\mathrm{df}=4$} & \multicolumn{2}{|c|}{$\mathrm{df}=4$} \\
\hline & & & \multicolumn{2}{|c|}{$p<.001$} & \multicolumn{2}{|c|}{$p>.05$} \\
\hline \multicolumn{7}{|c|}{$\begin{array}{c}\text { Table 3: Distribution of Male according to Socio-economic } \\
\text { Status }\end{array}$} \\
\hline
\end{tabular}
relation to age was found to be statistically significant $(\mathrm{p}<.001)$.

The prevalence of tobacco use, gradually increasing with the socio economic status, being minimum in lower socio economic status $(25.00 \%$ and $15.00 \%$ respectively) and maximum in upper socio economic status $38.70 \%$ and $35.48 \%$ respectively) with a little minor variation. The association was found statistically significant in case of smoking $(\mathrm{p}<001)$, while this is insignificant in case of smokeless form of tobacco abuse ( $p>0.05)$. 


\begin{tabular}{|c|c|c|c|c|c|c|}
\hline \multirow{2}{*}{$\begin{array}{l}\text { Sl. } \\
\text { No. }\end{array}$} & \multirow{2}{*}{ Education } & \multirow{2}{*}{ No. } & \multicolumn{2}{|c|}{ Smoking } & \multicolumn{2}{|c|}{ Smokeless } \\
\hline & & & No. & $\%$ & No. & $\%$ \\
\hline 1 & Illiterate & 391 & 102 & 26.08 & 98 & 25.06 \\
\hline 2 & $\begin{array}{c}\text { Junior High } \\
\text { School }\end{array}$ & 271 & 98 & 36.16 & 90 & 33.21 \\
\hline 3 & High School & 191 & 43 & 22.51 & 46 & 24.08 \\
\hline 4 & $>$ High School & 43 & 9 & 20.93 & 4 & 9.3 \\
\hline 5 & Total & 896 & 252 & 18.12 & 238 & 26.56 \\
\hline \multirow{3}{*}{\multicolumn{3}{|c|}{$\chi^{2}$}} & \multicolumn{2}{|c|}{$\chi^{2}=13.54$} & \multicolumn{2}{|c|}{$\chi^{2}=13.76$} \\
\hline & & & \multicolumn{2}{|c|}{$\mathrm{df}=3$} & \multicolumn{2}{|c|}{$\mathrm{df}=3$} \\
\hline & & & \multicolumn{2}{|c|}{$\mathrm{p}<.05$} & \multicolumn{2}{|c|}{$\mathrm{p}<.05$} \\
\hline
\end{tabular}

The prevalence of smoking and smokeless tobacco use is maximum among illiterate persons $(26.08 \%$ and $25.06 \%$ respectively) and minimum in persons educated for more than high school $(20.93 \%$ and $9.30 \%$ respect.) with a minor variation. The association was found statistically significant $(\mathrm{p}<0.05)$.

\begin{tabular}{|c|c|c|c|c|c|c|}
\hline \multirow{2}{*}{$\begin{array}{l}\text { Sl. } \\
\text { No. }\end{array}$} & \multirow{2}{*}{ Occupation } & \multirow{2}{*}{ No. } & \multicolumn{2}{|c|}{ Smoking } & \multicolumn{2}{|c|}{ Smokeless } \\
\hline & & & No. & $\%$ & No. & $\%$ \\
\hline 1 & Unemployed & 167 & 62 & 37.12 & 64 & 38.32 \\
\hline 2 & Student & 88 & 9 & 10.22 & 7 & 7.95 \\
\hline 3 & Labourer & 403 & 73 & 18.11 & 84 & 20.84 \\
\hline 4 & $\begin{array}{l}\text { Govt./Pvt. } \\
\text { Service }\end{array}$ & 89 & 41 & 46.06 & 33 & 37.07 \\
\hline 5 & Own Business & 149 & 67 & 44.96 & 50 & 33.55 \\
\hline 6 & & 896 & 252 & 28.12 & 238 & 26.56 \\
\hline \multirow{3}{*}{\multicolumn{3}{|c|}{$\chi^{2}$}} & \multicolumn{2}{|c|}{$\chi^{2}=75.70$} & \multicolumn{2}{|c|}{$\chi^{2}=43.00$} \\
\hline & & & \multicolumn{2}{|c|}{$\mathrm{df}=4$} & \multicolumn{2}{|c|}{$\mathrm{df}=4$} \\
\hline & & & \multicolumn{2}{|c|}{$\mathrm{p}<.001$} & \multicolumn{2}{|c|}{$\mathrm{p}<.001$} \\
\hline \multicolumn{7}{|c|}{$\begin{array}{c}\text { Table 5: Distribution of Study Subjects according to } \\
\text { Occupation and Tobacco Use }\end{array}$} \\
\hline
\end{tabular}

It is evident from table 15 that both forms of tobacco use was maximum in persons in Govt/Pvt. service, followed by those who were running their own business, then unemployed persons with minor variation. The prevalence was lowest among students. The difference in relation to occupation was statistically significant $(p<001)$.

\begin{tabular}{|c|c|c|c|c|c|c|}
\hline \multirow{2}{*}{ Sl. No. } & \multirow{2}{*}{ Marital Status } & \multirow{2}{*}{ No. } & \multicolumn{2}{|c|}{ Smoking } & \multicolumn{2}{c|}{ Smokeless } \\
\cline { 4 - 7 } & & No. & $\mathbf{\%}$ & No. & $\%$ \\
\hline 1 & Unmarried & 349 & 169 & 31.23 & 99 & 28.36 \\
\hline 2 & Ever Married & 547 & 143 & 26.14 & 139 & 25.41 \\
\hline 3 & & 896 & 252 & 28.12 & 238 & 26.56 \\
\hline \multirow{4}{*}{$\chi^{2}$} & $\chi^{2}=46.61$ & $\chi^{2}=0.95$ \\
\cline { 3 - 6 } & \multicolumn{2}{|c|}{$\mathrm{df}=1$} & \multicolumn{2}{c|}{$\mathrm{df}=1$} \\
\cline { 3 - 6 } & \multicolumn{2}{|c|}{$\mathrm{p}<.001$} & $\mathrm{p}>.05$ \\
\hline \multicolumn{3}{|c|}{ Table 6: Distribution of Study Subjects according } \\
to Marital Status
\end{tabular}

Use of smoke and smokeless tobacco was comparatively more in unmarried $(31.23 \%$ and $26.14 \%$ respectively) than ever married $(26.14 \%$ and $25.41 \%$ respectively). The difference in prevalence of smoking in relation to occupation was statistically significant $(\mathrm{p}<0.001)$, but this is insignificant in use of smokeless tobacco $(\mathrm{p}>0.05)$.

\begin{tabular}{|c|c|c|c|c|c|c|}
\hline $\begin{array}{c}\text { Sl. } \\
\text { No. }\end{array}$ & $\begin{array}{c}\text { Type of } \\
\text { Families }\end{array}$ & No. & \multicolumn{2}{|c|}{ Smoking } & \multicolumn{2}{c|}{ Smokeless } \\
\hline & & & No. & \% & No. & \% \\
\hline 1 & Nuclear & 491 & 146 & 29.73 & 148 & 30.14 \\
\hline 2 & Joint & 405 & 106 & 26.17 & 90 & 22.22 \\
\hline 3 & & 896 & 252 & 28.12 & 238 & 26.56 \\
\hline \multicolumn{3}{|c|}{$\chi^{2}$} & \multicolumn{2}{|c|}{$\chi^{2}=1.39$} & \multicolumn{2}{c|}{$\chi^{2}=7.14$} \\
\cline { 2 - 6 } & \multicolumn{2}{|c|}{$\mathrm{df}=1$} & \multicolumn{2}{c|}{$\mathrm{df}=1$} \\
\cline { 2 - 6 } & \multicolumn{2}{|c|}{$\mathrm{p}>0.05$} & \multicolumn{2}{c|}{$\mathrm{p}<0.05$} \\
\hline
\end{tabular}

Table 7: Distribution of Study Subjects according to type of Families

The prevalence of smoking and smokeless tobacco use was more in persons belonging to nuclear family $29.73 \%$ and $30.14 \%$ respectively) as compared to those in joint family ( $26.17 \%$ and $22.22 \%$ respectively). The prevalence of substance abuse in relation type of family was found to be statistically insignificant in case of smoking $(\mathrm{p}>0.05)$; however, the prevalence of smokeless tobacco abuse was found to be statistically significant $(\mathrm{p}<0.05)$.

\section{DISCUSSION}

In this study, the prevalence of tobacco use is $54.68 \%$. A large survey in 2001 showed that the prevalence of current tobacco use above 10 years of age in Uttar Pradesh was $50.0 \%$ among men $\& 9.1 \%$ among women. ${ }^{8}$

A high prevalence $(67.70 \%)$ was also reported in study of substance use in intercollege students in district Dehradun. ${ }^{9}$ A large cross-sectional study of adults in Mumbai found that $69 \%$ of males were tobacco users, with $24 \%$ using cigarettes or bidi. ${ }^{5}$ and it is estimated that $52-70 \%$ of males and $3-38 \%$ of females currently use tobacco in some form in different areas of India. ${ }^{10,11}$

The age wise analysis shows that as the age increases from 15 to 49 years the use of smokeless tobacco also increases from $9.94 \%$ to $35.39 \%$, followed by a little fall in the $50-59$ years $(35.10 \%)$ and $60+$ age group $(36.36 \%)$. The prevalence increased with increasing age which was also found in WHO-SEARO report. ${ }^{9}$ and NFHS-3 report. ${ }^{4}$

In this study, the prevalence of tobacco use, gradually increasing with the socioeconomic status contrary to WHOSEARO report. ${ }^{12}$ which says that higher family income levels were associated with a lesser prevalence of current tobacco use. Rani et al. (2003) ${ }^{13}$ and Subramanian et al (2004). ${ }^{14}$ have analysed the pattern and distribution of tobacco consumption and health behaviour of households in India with the NFHS-3 data. ${ }^{4}$ Socio-economic deference is more marked for smoking than for chewing tobacco.

In the present study, tobacco use was more prevalent among illiterate (25.06\% smokeless form, $26.08 \%$ smoking) as compared to literate one for more than high school $(9.30 \%$, $20.93 \%$ respectively). The negative association with educational status in this study is supported by WHO-SEARO report. ${ }^{9}$ for tobacco use in Uttar Pradesh \& Karnataka.

Influences of occupation on tobacco use was also enquired and observed in this study. Most of the tobacco users were doing service $(37.07 \%$ smokeless tobacco, $46.06 \%$ smoking) than those having own business $(33.35 \%$ and $4.96 \%$ respectively) followed by unemployed (38.82\% and $37.12 \%$ respectively), labourers $(20.84 \%$ and $18.11 \%$ respectively) and least common amongst the students $(7.95 \%$ and $10.22 \%$ respectively). This finding is supported by Sinha, et al(2001).15 in rural area of Bihar and Bala et al (2006)16 in 
Gujarat and NE region- annual report 1999-2000 reporting high prevalence of tobacco use among self-employed (53.7\% smokeless, $42.7 \%$ smoking) followed by employed (41.3\%, $52.4 \%$ respectively). Prevalence was low among students and unemployed.

In the present study, a small difference was observed when analysis about the influences of marital status on tobacco use was undertaken. Overall a little more of unmarried people $(28.36 \%$ smokeless tobacco, $31.23 \%$ smoking) are using either form of substances in this study population as compared to ever married people (25.41\% smokeless tobacco, 26.14\% smoking). This finding is supported by Bhonsle et al (1996). ${ }^{10}$ reporting tobacco use more common in those of unmarried people as compared to those of the married one, but not supported by Sinha et al (2001) ${ }^{15}$, Bala et al (2006). ${ }^{16}$

All type of substance use were found to be statistically more common in nuclear family in comparison to joint family (30.14\% for smokeless tobacco, 29.73\% for smoked form in nuclear family and $22.22 \%, 26.17 \%$ respectively in joint family which was almost similar to findings of WHO-SEARO report (2001) ${ }^{9}$ and NFHS-3 report. ${ }^{4}$ - "pattern of substance use is more common in small family".

\section{CONCLUSION}

This study shows that the prevalence of tobacco use gradually increases with increasing age and upper socioeconomic status. Literacy has positive impact on tobacco use. Findings suggest that prevalence is more among persons in Jobs; work pressure may be an important reason for tobacco use. Family size and marital status also impact on tobacco use indicating poor emotional support in a nuclear family and/or by spouse.

\section{STRENGTH}

The strength of the study was that the sampling of eligible subjects was done by systematic random sampling technique. The sample size is large enough to avoid biases. Based on observations an attempt was made in community for behavioural change regarding tobacco use.

\section{LIMITATIONS}

In spite of the best efforts to convince all the study subjects to participate in the study, some of them did not cooperate. Females were not included in this study which is another limitation, hence this study cannot be generalised to the entire reference population.

\section{RECOMMENDATIONS}

It was also felt during the study that there is a need to increase awareness regarding factors influencing tobacco use and its health hazards in the general population.

\section{REFERENCES}

1. WHO report on the global tobacco epidemic, 2011. The MPOWER package, warning about the dangers of tobacco. Geneva: WHO 2011.

2. Global Adult Tobacco Survey (GATS) India: 2009-2010. Published by IIPS, Mumbai and funded by the ministry of Health and Family Welfare, GOI 2010:65.

3. Jha P, Guindon GE, Joseph RA, et al. A rational taxation system of bidis and cigarettes to reduce smoking deaths in India. Econ Polit Wkly 2011;46(42):44-51.

4. International Institute for Population Sciences (IIPS) and Macro International. National Family Health Survey (NFHS-3), 2005-06. India: Mumbai: IIPS. Morbidity and Health Care 2007;1:426-8.

5. Tobacco: deadly in any form or disguise. Available from: http://www.who.int/tobacco/communications/events/w ntd/2006/Report_v8_4May06.pdf pp 10-15.

6. A WHO/The union monograph on TB and tobacco control. Joining efforts to control two related global epidemics 2010:8-10.

7. Pednekar MS, Gupta PC, Yeole BB, et al. Association of tobacco habits, including bidi smoking, with overall and site-specific cancer incidence: results from the Mumbai cohort study. Cancer Causes Control 2011;22(6):859-68.

8. Chaudhary K, Prabhakar AK, Prabhakaran PS, et al. Prevalence of tobacco use in Karnataka and Uttar Pradesh in India. New Delhi: Indian council of medical research and WHO 2001.

9. Juyal R, Bansal R, Kishore S, et al. Substance use among intercollege students in district Dehradun. Indian Journal Of Community Medicine 2006;31(4):252-5.

10. Gupta PC, Murti PR, Bhonsle RB. Epidemiology of cancer by tobacco products and the significance of TSNA. Critical Reviews in Toxicology 1996;26(2):183-98.

11. Gupta PC, Ball K. India: tobacco tragedy. Lancet 1990;335:594-5

12. Brief profile on gender and tobacco in South East Asia Region. Available from: http://www.searo.who.int/tobacco/data/gender_tobacc.

13. Rani $M$, Bonu $S$, Jha $P$, et al. Tobacco use in India: prevalence and predictors of smoking and chewing in a national cross sectional household survey. Tobacco Control 2003;12(4):e4.

14. Subramanian SV, Nandy S, Irving $M$, et al. Role of socioeconomic markers and state prohibition policy in predicting alcohol consumption among men and women in India: A multilevel statistical analysis. Bulletin Of World Health Organization 2005;83(11):829-36.

15. Sinha DN, Gupta PC, Pedenekar MS. Tobacco use among students in eight North-eastern states of India. Indian J Cancer 2003;40(2):43- 59.

16. Bala DV, Bodiwala NI, Patel DD, et al. Epidemiological determinants of tobacco use in Gujarat state, India. Indian Journal of Community Medicine 2006;31(3):173-6. 